\title{
MANAGEMENT OF MAGNETIC INTRAOCULAR FOREIGN BODY
}

\author{
Malla O K*, Sharma A K*, Shrestha $\mathrm{S}^{\star}$
}

\section{ABSTRACT}

Posterior segment intraocular foreign bodies pose a problem in restoration of significant visual acuity usually due to delayed presentation, improper evaluation and management. However, good history taking, meticulous ocular examination and proper management can result in reasonable visual acuity in cases of retained intraocular foreign body in the posterior segment. We are presenting a case report of penetrating ocular trauma with retained intraocular foreign body in the posterior segment. Following intraocular foreign body removal, core vitrectomy and subsequent cataract extraction, the patient had best corrected visual acuity of $6 / 9$.

Key Words: Intraocular foreign body, vitrectomy, cataract.

\section{INTRODUCTION}

Penetrating eye injuries with intraocular foreign bodies (IOFB) are not infrequent. One of the most common intraocular foreign bodies (IOFBs) are chips of iron and steel $(90 \%)^{1}$. In penetrating eye injuries, posterior segment is the commonest site $(70 \%)^{2}$, where intraocular foreign bodies (IOFB) are lodged. By and large IOFBs are magnetic in nature and such magnetic IOFBs lying in the vitreous cavity or in the retina are sometimes managed with the help of external magnets. Ideally, a vitrectomy procedure and IOFB removal with forceps or intraocular magnet via enlarged sclerotomy is advocated, depending on the size of the IOFB. A penetrating eye injury with retained IOFB damages the ocular structures by its mechanical effect, reaction to IOFB, post-traumatic inflammatory reactions or by the onset of infection (post traumatic endophthalmitis). Such injuries in fact sometimes pose a problem in their management. Vitrectomy offers a method that allows a traumatic IOFB removal and simultaneous treatment of tissue injuries such as removal of media opacity and repair of retinal lesion ${ }^{4}$. We here report the management of a case of penetrating ocular trauma with a retained magnetic IOFB.

\section{CASE REPORT}

Mr. P.P., 25 year of age, attended the outpatient service at Nepal Eye Hospital, with chief complaints of pain and cloudy vision following injury to the right eye while hammering. The incident had occurred a few hours prior to presentation. On examination, the left eye was normal with a visual acuity of $6 /$ 6. Visual acuity in the right eye was $6 / 36$, and improved to $6 /$ 9 with pin hole. There was a self-sealing penetrating injury in the cornea inside the limbus at 6 o'clock. There was a hole in the iris and a localized cataract corresponding to the corneal wound. The intraocular pressure (IOP) was $10 \mathrm{~mm} \mathrm{Hg}$. On detailed fundus examination after mydriasis, an IOFB was noted impregnated in the retina in the inferotemporal quadrant. The retina around the foreign body was slightly elevated. The vitreous was clear. Plain x-ray of the orbit in the anteriorposterior and lateral view showed radio-opaque foreign body. B-scan ultrasonography (USG) located the IOFB embedded in the retina. Preoperatively, argon laser photocoagulation was performed around the IOFB outside the elevated retina. Under local anaesthesia, during surgery after par plana vitrectomy mainly around the IOFB, the foreign body was dislodged and removed with the help of an external magnet without much

* Nepal Eye Hospital, Tripureshwor, Nepal.

Address for correspondence : $\quad$ Dr. O. K. Malla

Nepal Eye Hospital, Tripureshwor, Nepal.

Email: eyehospital@mos.com.np 
Fig. 1

\section{Fig.1 : Intraocular Foreign Body}

difficulty. Postoperatively, the vision remained clear and the retina remained attached/ Subsequently on follow up visits, the patient noted a gradual diminution of vision because of his progressive cataract. The cataract gradually reduced his vision to hand motions. He electively underwent extracapsular cataract extraction with posterior chamber intraocular lens implantation (ECCE/PC IOL) in the affected right eye. On the operating table, a rent in the posterior capsule was noted, but introduction of the IOL was manageable. He was reviewed in the outpatient department .His visual acuity in the operated eye was 6/12 unaided with PCIOL centered in the capsular bag. The retina was in place (Fig.1) and appeared healthy.

\section{DISCUSSION}

Penetrating ocular injury with retained IOFBs can at times be very cumbersome to manage. The need of a careful preoperative evaluation, a detailed history and a thorough clinical examination is impoprtant. Investigations in the form of $\mathrm{X}$ - rays, USG and when necessary CT scan are required for proper localization of the FB in the eye $\mathrm{e}^{3}$ as well as for medico-legal purposes and for documentation. Removal of a magnetic IOFB by and large is relatively simple, but at times it can be difficult. Magnetic IOFB embedded in the retina and of a longer duration are to be approached with caution. They can be real problems. In our case, the history of IOFB entry into the eye was short, the media was relatively clear and the IOFB could be seen lying in the retina. Preoperatively, laser photocoagulation could be applied around the foreign body thus securing the retina. Invariably, it is required to dislodge the foreign body which had traversed with a rent in the posterior capsule of the lens. The rent as a matter of fact was of moderate size to allow a routine ECCE and PCIOL implantation. Excessive manipulation was unnecessary. In the management of penetrating ocular injuries with retained IOFBs, final visual recovery is of utmost important and our patient's best corrected visual acuity was $6 / 9$.

\section{REFERENCES}

1. Khurana, A.K. "Ocular Injuries", Ophthalmology, 2000, 376381 .

2. Deborrah Pavan- Langston. "Burns and Trauma", Manual of Ocular Diagnosis and Therapy. 1996; 40-41.

3. Serge De Bustros. "Posterior Segment Intraocular Foreign Bodies", Eye Trauma. 1991, 226-235.

4. Gillbert Grand M., Bressler N.M. Brown G.C. et al, "Posterior Segment Trauma". Basic and Clinical Science Course, Retina and Vitreous, 1998-1999, 219.

5. Viktoria Mester MD, Ference Kuhn MD. "Management of Posterior Segment Intraocular Foreing Bodies", Current Practice and Future Trends, International Classification of Ocular Trauma, The BETT, August 1999, 123-131.

\title{
ORTHOCON 2004
}

\section{Kathmandu, Nepal \\ 2 - 4th April, 2004}

\section{Jointly organized by}

Nepal Orthopaedic Association

President

Dr. Achyut Rajbhandari
Orthopaedica Belgica

President

BVOT Dr. Jan Victor

SORBCOT Dr. Jacques Magotteaux

\author{
Nepal Orthopaedic Association (NOA) \\ NMA Building, Siddhi Sadan, Exhibition Road \\ GPO Box: 189, Kathmandu, Nepal \\ Tel.: 4225860, 4231825, Fax: 977-1-4225300 \\ Email: noa@healthnet.org.np
}

